\title{
Estudo do Potencial Antioxidante em Amostras de Farinha de Resíduos de Processamento de Acerola, Tangerina e Graviola.
}

\author{
SENA, D. N. ${ }^{1}$; SOUSA, M.M.A. ${ }^{1}$; SOUSA, P. H. M. ${ }^{2}$; ALMEIDA, M. M. B. ${ }^{3}$; \\ ${ }^{1}$ Aluna de graduação em Engenharia de Alimentos da UFC - Campus do Pici; \\ ${ }^{2}$ Docente da UFC - Campus do Pici, do Instituto de Cultura e Arte. \\ ${ }^{3}$ Docente da UFC - Campus do Pici, do Departamento de Química Analítica e Físico-Química. \\ E-mail: deborasnascimento@gmail.com
}

\begin{abstract}
RESUMO - Compostos antioxidantes são importantes na prevenção do desencadeamento das reações oxidativas, Os resíduos foram cedidos por indústrias produtora de polpa congelada de frutas, estes foram assim, objetivo do presente trabalho foi quantificar o total de compostos fenólicos e de carotenoides, assim como avaliar o potencial antioxidante em amostras de farinha de Acerola, Graviola e Tangerina. Verificou-se a atividade antioxidante variou entre 78,85 $\mu \mathrm{g} / \mathrm{g}$ (tangerina) e 310,77 $\mu \mathrm{g} / \mathrm{g}$ (graviola). Os teores de fenóis totais variaram entre 13,23 mg/100g (acerola) e 21,44 $\mathrm{mg} / 100 \mathrm{~g}$ (manga) já os teores de Carotenoides variam entre $0,4 \mathrm{mg} / 100 \mathrm{~g}$ (Acerola) e $0,1 \mathrm{mg} / 100 \mathrm{~g}$ (tangerina), em ambos os casos são valores baixos se comparados aos encontrados que a literatura para outras frutas.
\end{abstract}

\section{INTRODUÇÃO}

Nos últimos anos, uma quantidade substancial de evidências tem indicado o papel chave dos radicais livres e outros oxidantes como grandes responsáveis pelo envelhecimento e pelas doenças degenerativas associadas ao envelhecimento, como câncer, doenças cardiovasculares, catarata, declínio do sistema imune e disfunções cerebrais (SOUSA et. al., 2007).

Os radicais de oxigênio (radicais hidroxila e peroxila) e o ânion superóxido têm um papel importante nas reações bioquímicas/fisiológicas do corpo humano. No entanto, se houver produção excessiva de radicais de oxigênio durante os processos patofisiológicos ou devido a fatores ambientais adversos e não existirem antioxidantes disponíveis in vivo, podem ocorrer doenças e danos profundos em tecidos (DUARTE-ALMEIDA et. al., 2006).

A produção de radicais livres é controlada nos seres vivos por diversos compostos antioxidantes, os quais podem ter origem endógena (por ex., superóxido dismutase), ou serem provenientes da dieta alimentar e outras fontes. Destas últimas destacam-se tocoferóis (vitamina E), ácido ascórbico (vitamina C), polifenóis, selênio e carotenoides (SOUSA et. al., 2007a). Tais 
substancias, chamadas antioxidantes, são substâncias que retardam a velocidade da oxidação, através de um ou mais mecanismos, tais como inibição de radicais livres e complexação de metais assim, objetivo do presente trabalho foi quantificar o total de compostos fenólicos e de carotenoides (DUARTE-ALMEIDA et. al., 2006).

Quando há limitação na disponibilidade de antioxidantes podem ocorrer lesões oxidativas de caráter cumulativo. Os antioxidantes são capazes de estabilizar ou desativar os radicais livres antes que ataquem os alvos biológicos nas células(SOUSA et. al., 2007a).

O consumo de frutas cada vez mais se torna crescente devido ao valor nutritivo e aos efeitos terapêuticos, pois além dos nutrientes essenciais e de micronutrientes como minerais, fibras e vitaminas, possuem diversos metabólitos secundários como os polifenóis e inúmeros compostos com capacidade antioxidante, os quais capturam radicais livres, por conseguinte propiciando a redução do risco de doenças crônicas não transmissíveis, tais como câncer, doenças cardiovasculares e cerebrovasculares, processos inflamatórios, etc. (KUSKOSKI et al., 2006; HARBONE e WILLIAMS, 2000).

Neste setor, além da demanda por frutas frescas é crescente o mercado de sucos e polpas, por preservarem as características químicas e sensoriais da fruta fresca e o consumidor poderem encontrá-las durante o ano todo, sem ter que se preocupar com a época e o amadurecimento da fruta (SOUSA et al., 2011). Como consequência, o aumento deste processamento gera cerca de $40 \%$ dos resíduos agroindustriais, composto de restos de polpa, casca, caroços ou sementes. Estes resíduos podem, por sua vez, ser utilizados no desenvolvimento de novos produtos alimentícios, aumentando seu valor agregado, pois muitos deles são ricos em nutrientes minerais, fibra alimentar e compostos bioativos, amplamente reconhecidos pelas suas propriedades promotoras de saúde tais como antioxidantes e antimicrobianos (ABUD, 2009), assim, o presente trabalho tem como objetivo avaliar o potencial antioxidante em amostras de farinha de resíduos de acerola (Malpighia glabra), graviola (Annona muricata) e tangerina (Citrus reticulata).

\section{METODOLOGIA}

Nas indústrias, os resíduos das frutas, logo após a extração, serão acondicionados em sacos plásticos, armazenados em câmara de congelamento e posteriormente transportados para o Laboratório de Frutas e Hortaliças da Universidade Federal do Ceará, onde serão mantidos em freezer a $-14{ }^{\circ} \mathrm{C}$. Depois de descongelados à temperatura ambiente, as amostras serão lavadas em água corrente e higienizadas com água clorada a partir de hipoclorito de sódio a 100 ppm por 5 min. Posteriormente, serão desidratados em estufa de circulação forçada de ar sob temperatura de $65^{\circ} \mathrm{C}$., onde a transferência de calor ocorre por convecção forçada de ar quente, até peso constante. Após a desidratação, serão trituradas com o auxílio de um processador e peneiradas para se obter pós de 
granulometria variando entre $0,50 \mathrm{~mm}$ a $1,00 \mathrm{~mm}$. Os produtos em pó, assim obtidos, serão armazenados em recipientes de vidro, devidamente identificados e estes recipientes, mantidos sob $\mathrm{t}$ Nas indústrias, os resíduos das frutas, logo após a extração, foram acondicionados em sacos plásticos, armazenados em câmara de congelamento e posteriormente transportados para o Laboratório de Frutas e Hortaliças da Universidade Federal do Ceará, onde foram mantidos em freezer a $-14^{\circ} \mathrm{C}$. Depois de descongelados à temperatura ambiente, as amostras foram lavadas em água corrente e higienizadas com água clorada a partir de hipoclorito de sódio a 100 ppm por 5 min. Posteriormente, foram desidratados em estufa de circulação forçada de ar sob temperatura de $65^{\circ} \mathrm{C}$, , onde a transferência de calor ocorre por convecção forçada de ar quente, até peso constante. Após a desidratação, foram trituradas com o auxílio de um processador e peneiradas para se obter pós de granulometria variando entre $0,50 \mathrm{~mm}$ a $1,00 \mathrm{~mm}$. Os produtos em pó, assim obtidos, foram armazenados em recipientes de vidro, devidamente identificados e estes recipientes, mantidos sob temperatura ambiente, foram envolvidos em papel alumínio e em filme de PVC.

Para o preparo do extrato utilizado na determinação do potencial antioxidante e polifenóis totais adicionou-se $20 \mathrm{~mL}$ de etanol $50 \%$ a $1 \mathrm{~g}$ da amostra, agitou-se manualmente com bastão de vidro, a mistura permaneceu em repousar, no escuro, por $1 \mathrm{~h}$, e centrifugada por 15 minutoa a 10.000rpm em centrifuga da marca: Hettich Zentrifugen, modelo: Rotina 380R. Em seguida, o sobre nadante foi recolhido em balão âmbar de $50 \mathrm{~mL}$. Os resíduos que permaneceram no filtro foram re-extraídos, agora utilizando acetona $50 \%$, e o segundo sobrenadante adicionado ao primeiro. Os extratos foram condicionados em frascos âmbar secos sob atmosfera de nitrogênio e armazenados à $-18^{\circ} \mathrm{C}$ ate o momento das análises.

A capacidade antioxidante foi determinada total pelo método ABTS com algumas modificações. Primeiramente o radical ABTS foi gerado através da reação de $5 \mathrm{~mL}$ de solução aquosa de ABTS $(7 \mathrm{mM})$ e $88 \%$ u03BCL de solução de persulfato de potássio a $140 \mathrm{mM}(2,45 \mathrm{mM}$ concentração final). A mistura permaneceu no escuro por 14h e só depois foi diluída com etanol para a obtenção da absorbância de 0,7 $\pm 0,02$ a $734 \mathrm{~nm}$ usando um espectrofotômetro de marca SHIMADZU, modelo UV-1800. Em seguida, uma amostra de $30 \mu \mathrm{L}$ do extrato dos resíduos das farinhas das frutas e do antioxidante padrão Trolox (ácido 2-carboxilico-6-hidroxi-2, 5, 7,8tetrametilcromano), tomados como referência, reagiram com $3 \mathrm{~mL}$ da solução resultante do radical ABTS no escuro. O decréscimo da absorbância a $734 \mathrm{~nm}$ foi medido após 6 min, com o auxílio de uma curva padrão entre 500-1500 $\mu \mathrm{M}$ de Trolox. Os resultados foram expressos como $\mu \mathrm{M}$ de capacidade antioxidante equivalente ao Trolox (TEAC) por grama de massa fresca.

Os polifenóis totais foram determinados de acordo com a metodologia descrita por Reynertson et al. (2008), utilizando o reagente Folin-Ciocalteau. As amostras foram analisadas em triplicata e quantificadas através da construção de curva padrão de ácido gálico $(0,01$ a 0,2 mg de 
ácido gálico. mL-1) e os resultados foram expressos em mg ácido gálico.g ${ }^{-1}$ (FOLIN, 1927).

A determinação dos carotenoides totais foi realizada apartir da extração com $1 \mathrm{~g}$ de amostra em $10 \mathrm{~mL}$ de solução extratora acetona: hexano (4:6), a solução foi posta em tubo de ensaio e homogeneizada por $1 \mathrm{~min}$. As leituras foram realizadas em espectrofotômetro UV-vis (Micronal, Modelo B582) nos comprimentos de onda de $453 \mathrm{~nm}, 505 \mathrm{~nm}, 645 \mathrm{~nm}, 663 \mathrm{~nm}$. O resultado foi expressos em mg/100g $\beta$ caroteno.

\section{RESULTADOS E DISCURSÕES}

Ao analisarmos os resultados expostos na Tabela 1, podemos verificar que a atividade antioxidante das amostras variou entre 78,85 $\mu \mathrm{g} / \mathrm{g}$ (tangerina) 310,77 $\mu \mathrm{g} / \mathrm{g}$ (graviola). Kuskoski et. al. (2006) em estudo sobre atividade antioxidante, polifenóis e antocianinas em frutos tropicais silvestres e polpas de frutas congeladas encontro valores inferiores aos encontrados nesse estudo para a polpa de graviola $(84,3 \mathrm{mg} / 100 \mathrm{~g})$ e superiores para polpa de acerola $(580,1 \mathrm{mg} / 100 \mathrm{~g})$.

Tabela 1 - valores de polifenóis, carotenoides e atividades antioxidante em farinha de resíduos de frutas tropicais.

\begin{tabular}{cccc}
\hline Amostra & $\begin{array}{c}\text { Polifenóis Totais } \\
(\mathbf{m g} / \mathbf{1 0 0 g})\end{array}$ & $\begin{array}{c}\text { Carotenoides totais } \\
\mathbf{( m g / 1 0 0 g )}\end{array}$ & $\begin{array}{c}\text { Atividade } \\
\text { Antioxidante }(\boldsymbol{\mu g} / \mathbf{g})\end{array}$ \\
\hline Acerola & 13,23 & 0,42 & 247,24 \\
Graviola & 13,71 & 0,43 & 310,77 \\
Tangerina & 21,44 & 0,3 & 78,85 \\
\hline
\end{tabular}

Os teores de polifenóis totais variou entre $13,23 \mathrm{mg} / 100 \mathrm{~g}$ (acerola) e 21,44 mg/100g (graviola), Kuskoski et al. (2005) encontraram valor de polifenóis totais de $136,80 \mathrm{mg} / 100 \mathrm{~g}$ de polpa de açaí, superiores aos encontrados nas farinhas aqui estudadas. Os compostos fenólicos são os maiores responsáveis pela atividade antioxidante em frutos (HEIM et al., 2002). Embora a vitamina $\mathrm{C}$ seja considerada por alguns autores como o maior contribuinte na atividade antioxidante, diversos estudos mostram que a contribuição da vitamina $\mathrm{C}$ e outros compostos na determinação da atividade antioxidante de frutos e derivados é baixa e afirmam que a maior contribuição para a atividade antioxidante total de frutos se deve à composição de compostos fitoquímicos .como polifenóis (KUSKOSKI et. al., 2006).

Os teores de carotenoides variaram entre $0,43 \mathrm{mg} / 100 \mathrm{~g}$ (graviola) e $0,3 \mathrm{mg} / 100 \mathrm{~g}$ (tangerina), Souza (2007) encontrou uma média geral de carotenoides para frutos de açaí de $5,07 \mathrm{mg} / 100 \mathrm{~g}$, cujo valor mínimo foi de 3,88 mg/100 g, valores bem superiores aos apresentados nesse estudo. Já DOS SANTOS et al. (2008), em estudo em estudo sobre Correlação entre atividade antioxidante e compostos bioativos de polpas comerciais de açaí encontrou teor de carotenóides totais de 0,21 a $3,84 \mathrm{mg} / 100 \mathrm{~g}$, assim, os valores encontrados no presente estudo se assemelham aos encontrados por 
esse autor para certas marcas de polpas comerciais de açaí.

\section{CONCLUSÕES}

Concluímos com o presente trabalho que as amostras estudadas apresentam em sua composição concentrações consideráveis de substancias antioxidantes, o que a torna atrativa comercialmente pro sua ação antioxidante, sendo esta influenciada especialmente pela quantidade de substancias fenólica presentes na amostra.

\section{REFERÊNCIAS BIBLIOGRÁFICAS}

ABUD, A. K. S.; NARAIN, N. Incorporação da farinha de resíduo do processamento de polpa de fruta em biscoitos: uma alternativa de combate ao desperdício. Brazilian Journal of Food Technology, v. 12, n. 4, p. 257-265, 2009.

DOS SANTOS,G.M.; MAIA,G.S.; SOUSA,P.H.M.; COSTA,J.M.C.; FIGUEIREDO, R.W.; PRADO,G.M. Correlação entre atividade antioxidante e compostos bioativos de polpas comerciais de açaí (Euterpe oleracea Mart). Archivos Latinoamericanos De Nutricion, V. 58, n.2, 2008.

DUARTE-ALMEIDA,J.M.;SANTOS,R.J.;GENOVESE,M.I.; LAJOLO,F.M. Avaliação Da Atividade Antioxidante Utilizando Sistema B-Caroteno/Ácido Linoléico E Método De Seqüestro De Radicais DPPH•. Ciênc. Tecnol. Aliment., Campinas, 26(2): 446-452, abr.-jun. 2006.

FOLIN, C.; CIOCALTEU, V. Tyrosine and tryptophan determination in proteins. J Biol Chem, v.73, p.627-650, 1927.

HARBONE, J. B.; WILLIAMS, C. A. Advances in flavonoid research since 1992. Phytochemistry,v. 55, p. 481-504, 2000.

HEIM, K.E. et al. Flavonoid antioxidants: chemistry,metabolism and structure-activity relationships. J NutrBiochem,v.13, p.572-584, 2002.

Kuskoski EM, Asuero AG, Troncoso AM, Mancini-Filho J, Fett R. Aplicacion de diversos métodos químicos para determinar actividad antioxidant en pulpa de frutos. Cienc. Tecnol. Aliment.,Campinas, v.25, n.4, p.726-732, 2005.

KUSKOSKI, E. M.; ASUERO, A. G.; ORALES, M. T.; FETT, R. Frutas tropicais silvestres e polpas congeladas: atividade antioxidante, polifenóis e antocianinas. Ciência Rural, v. 36, n. 4,p.1283-1287, 2006.

REYNERTSON, K. A.; YANG, H.; JIANG, B.; BASILE, M. J.; KENNELLY, E. J. Quantitative analysis of antiradical phenolic constituents from fourteen edible Myrtaceae fruits. Food Chemistry, London, v. 109, n. 4, p. 883-890, 2008.

SOUSA,C.M.M.; SILVA,H.R.; GERARDO MAGELA VIEIRA-JR.,G.M.; AYRES, M.C.C.; COSTA,C.L.S.; ARAÚJO,D.S.; CAVALCANTE,L.C.D.; BARROS,E.D.S.; ARAÚJO,P.B.M.; BRANDÃO,M.S.; CHAVES,M.H. Fenóis Totais E Atividade Antioxidante De Cinco Plantas Medicinais. Quim. Nova,Vol. 30, n. 2, 351-355, $2007 \mathrm{a}$. 
SOUZA, M.C. de. Qualidade e Atividade Antioxidante de Frutos de Diferentes Progênies de Açaizeiro (Euterpe oleraceaMart). 2007. 125f. Dissertação (Mestrado em Tecnologia de Alimentos) - Departamento de Tecnologia de Alimentos, Universidade Federal do Ceará, Fortaleza, 2007.

SOUSA, M. S. B.; VIEIRA, L. M.; SILVA, M. J. M., LIMA, A. Caracterização Nutricional e Compostos Antioxidantes em Resíduos de Polpas de Frutas Tropicais. Ciência e Agrotecnologia, v. 35, n. 3, p. 554-559, 2011. 